\title{
The Impact of Urbanization on the Temporal and Spatial Evolution of Air Quality: A Case Study of Hubei Province
}

\author{
Shiyu Yang \\ Urban Studies Department, The University of Sheffield, Sheffield, UK \\ Email: yangshiyuchn@outlook.com
}

How to cite this paper: Yang, S. Y. (2021). The Impact of Urbanization on the Temporal and Spatial Evolution of Air Quality: A Case Study of Hubei Province. Current Urban Studies, 9, 659-676. https://doi.org/10.4236/cus.2021.94039

Received: September 30, 2021

Accepted: October 26, 2021

Published: October 29, 2021

Copyright ( 2021 by author(s) and Scientific Research Publishing Inc. This work is licensed under the Creative Commons Attribution International License (CC BY 4.0).

http://creativecommons.org/licenses/by/4.0/ (c) (i) Open Access

\begin{abstract}
The rapid urbanization in China in the last decade has brought about severe air pollution problems. To provide a theoretical basis for improving the air environment, this paper analyses air quality's spatial and temporal evolution in 13 prefecture-level cities in Hubei Province. It analyses the influence of various urbanization indicators on the AQI. Based on the existing literature, this paper selects six indicators to measure the level of urbanization of each city in three dimensions: population, economy and urbanization of land, and then uses the AQI of 13 prefecture-level cities in Hubei Province from 2015 to 2017 as the basis to analyze the annual and monthly changes of AQI values in each city in Hubei Province over three years and uses ArcGIS to make AQI values spatial distribution map. The urbanization index was then regressed on the AQI values to study the impact of urbanization level on the spatial and temporal evolution of air quality in each prefecture-level city in Hubei Province.
\end{abstract}

\section{Keywords}

Urbanization, Air Quality, Spatial and Temporal Evolution, Hubei Province

\section{Introduction}

Since the reform and opening-up, China has entered a period of rapid urbanization, with the urbanization rate rising from $17.92 \%$ in 1978 to $60.60 \%$ in 2019 . (Qiu \& Huang, 2020). This development in urbanization has several benefits, such as increased infrastructure and social services, making people's lives more convenient and comfortable. In terms of industrial progress and technological innovation, urbanization has created lots of wealth. However, growing urbanization has serious environmental consequences in many cities. In particular, com- 
pound air pollution problems such as haze, photochemistry and air pollution smog are becoming increasingly prominent (Chan \& Yao, 2008). People's health is adversely damaged by severe air pollution conditions like haze. Therefore the factors impacting air quality must be studied in detail in terms of spatial and temporal evolution.

Hubei province, at the heart of the Yangtze River's middle reach, is a driving force behind the rise of the central area. It is vital in China's regional growth. To develop industrial structure, plan industrial layout, and formulate environmental regulations, it is vital to examine the spatial-temporal evolution features and influence air quality parameters in the region. However, most available studies only look at one facet of urbanization's impact on air quality. There is no comprehensive framework of urbanization to discuss its impact on the air environment. The index used to measure urban air quality only measures a few common contaminants, which does not reflect China's current situation of compound air pollution. Therefore, this paper established a comprehensive urbanization system from multiple dimensions and chose an air quality index that integrates various major pollutants to characterize the air quality situation and provided a theoretical basis for identifying the specific causes affecting air quality in Hubei province as well as providing targeted solutions.

\section{Literature Review}

As urbanization progresses, new urban diseases have emerged. Air pollution has gotten a lot of attention since it affects people's lives and health. Experts and researchers in relevant domains have conducted extensive research on the characteristics of the spatial and temporal distribution of the atmospheric environment and its influencing elements.

The air quality in China is worse in the north and better in the south, according to the spatial and temporal distribution of pollution. The overall trend in air quality in China's provinces from 2014 to 2016 was positive, according to some scholars (Xu, Liu, \& Wang, 2019). On finds significant differences in the air environment with quarterly changes in each region's AQI based on monthly average values. Summer $>$ Autumn $>$ Spring $>$ Winter, according to some researchers (Xiao et al., 2017). The AQI quarterly variation is met by most regions in China. Spring in northwest China has the worst air quality, while summer air quality is good. This is due to factors like industrial layout and climatic conditions.

The literature currently available divides the factors influencing air quality into three main categories. These are local emissions, transport dispersion, and regeneration. First, most studies conclude that coal combustion, industrial emissions, and vehicle exhaust are the major sources of air pollution. Even though housing construction area, industrial sulphur dioxide, and residential car ownership statistics fluctuate, they are significantly correlated with AQI values (Cai \& $\mathrm{Li}, 2015)$. These are the main determinants of air quality. Second, studies have concluded that climate influences pollutant dispersion. In addition to the above 
factors, increased coal consumption and static atmospheric weather during the heating season contribute to increased air pollution in the autumn and winter (Wang, Xue, \& Zhang, 2016). Spring and summer air pollution reduction relies on increased wind and precipitation. Wind, rain, and unstable atmospheric conditions all play a role in the diffusion and dilution of air pollution. Third, many experts and scholars have overlooked the regeneration of pollutants. In the Beijing-Tianjin-Hebei region, (Sun et al., 2011) found that strong photochemical regeneration of secondary organic matter is the main component of regional fine particle pollution.

The discharge of pollution sources is a major factor affecting air quality. It is most closely related to human activities, so which activities will lead to the discharge of pollutants from the source? Rapid urbanization has led to many urban diseases and indirectly affected the air environment. The relationship between urbanization and air quality has been studied from various angles by scholars. Many scholars (Wang, Xie, \& Yue, 2015) believe that increasing urban population density will inevitably increase fuel consumption, causing urban residents to drive more frequently, causing large amounts of emissions. These findings all affect air quality. The most famous debate about economic cities is whether they follow the Environmental Kuznets Curve (EKC). Some scholars believe that the relationship between urbanization and air quality in China does not follow the classic inverted U-shaped curve, and that the evolution curves for different pollutants vary (Ding et al., 2016). However, some studies show an EKC curve between urban economic growth and pollutant emissions (Ma, Han, \& Yang, 2016). For example, the author noted that increasing the proportion of secondary industry will deteriorate air quality, while upgrading industrial structure will promote the reduction of pollution emissions. From the perspective of land urbanization, the expansion of urban land scale will result in more air pollution (Sun \& Zhong, 2017). Some experts say there is no strong link between urbanization and air quality. The coordination degree between the comprehensive environmental air quality index of 73 major Chinese cities and China's urbanization quality was calculated. The air quality of most cities was found to be moderately or barely matched to the urbanization level (Guo, Wang, \& Gao, 2014).

However, most existing studies have looked at the impact of urbanization on air quality from a single perspective, lacking a multidimensional and holistic approach. A single pollutant indicator is used to characterize air quality. To characterize the level of urbanization and air quality more scientifically, this paper uses the Air Quality Index (AQI) concept proposed in 2012 to characterize the situation comprehensively. China's regional development pattern relies on $\mathrm{Hu}-$ bei Province as the core and pivot of the Yangtze River Central River Urban Agglomeration Strategy. Thus, understanding the spatial and temporal evolution of air quality in the region is critical to improving industrial structure, planning industrial layout, and developing environmental regulations. So Hubei province is used to study the effects of urbanization on air quality. 


\section{Related Conceptual and Theoretical Studies}

\subsection{Air Quality Index (AQI)}

The AQI is an ambient air quality index proposed in the Ambient Air Quality Standard (GB3095-2012) jointly released by the Ministry of Environmental Protection and the State General Administration of Quality Supervision, Inspection and Quarantine in early 2012. The AQI was created against the background that the Air Pollution Index (API), which had previously been used to assess air quality in China, was often inconsistent with the public's actual perceptions due to several factors. AQI concept was introduced to provide a more realistic and accurate picture of air quality levels in China and to optimize the air quality measurement system.

\subsection{Air Quality Index Calculation Methodology}

A variety of pollutants are first converted into an air quality sub-index (IQAQI) according to their respective concentration limit standards (Table 1). Then the maximum of these is taken as the AQI value. The specific calculation formula is shown in Equations (1) and Equation (2).

The air quality sub-index for pollutant item $\mathrm{P}$ is IAQIp.

$$
\text { IAQIp }=\frac{\operatorname{IAQI}(\mathrm{Hi})-\mathrm{IAQI}(\mathrm{Lo})}{\mathrm{BP}(\mathrm{Hi})-\mathrm{BP}(\mathrm{Lo})}(\mathrm{Cp}-\mathrm{Bp}(\mathrm{Lo}))+\mathrm{IAQI}(\mathrm{Lo})(1)
$$

where: IAQIp - the air quality sub-index of pollutant item $\mathrm{p}$;

$\mathrm{Cp}$ - the mass concentration value of pollutant item $\mathrm{p}$;

$\mathrm{BP}(\mathrm{Hi})$ - the high value of the concentration limit of the pollutant in Table 2 that is similar to $\mathrm{Cp}$;

$\mathrm{BP}(\mathrm{Li})$ - the high value of the concentration limit of the pollutant in Table 2 that is similar to $\mathrm{Cp}$;

IAQI $(\mathrm{Hi})$ - the air quality sub-index in Table 2 corresponding to $\mathrm{BP}(\mathrm{Hi})$;

IAQI $(\mathrm{Li})$ - the air quality sub-index corresponding to $\mathrm{BP}(\mathrm{Li})$ in Table 2.

Table 1. Air quality sub-indices and corresponding concentration limits for pollutant items.

\begin{tabular}{cccccccc}
\hline IAQI & $\begin{array}{c}\mathrm{SO}_{2} \\
24-h o u r \\
\text { average } \\
\left(\mu \mathrm{g} / \mathrm{m}^{3}\right)\end{array}$ & $\begin{array}{c}\mathrm{SO}_{2} \\
1 \mathrm{hour} \\
\text { average } \\
\left(\mu \mathrm{g} / \mathrm{m}^{3}\right)\end{array}$ & $\begin{array}{c}\mathrm{NO}_{2} \\
24-\mathrm{hour} \\
\text { average } \\
\left(\mu \mathrm{g} / \mathrm{m}^{3}\right)\end{array}$ & $\begin{array}{c}\mathrm{NO}_{2} \\
1 \text { hour } \\
\text { average } \\
\left(\mu \mathrm{g} / \mathrm{m}^{3}\right)\end{array}$ & $\begin{array}{c}\mathrm{CO} \\
24 \text {-hour } \\
\text { average } \\
(\mathrm{mg} / \mathrm{m} 3)\end{array}$ & $\begin{array}{c}\mathrm{CO} \\
1 \text { hour } \\
\text { average } \\
(\mathrm{mg} / \mathrm{m} 3)\end{array}$ & $\begin{array}{c}\mathrm{O}_{3} \\
1 \text { hour } \\
\text { average } \\
\left(\mu \mathrm{g} / \mathrm{m}^{3}\right)\end{array}$ \\
\hline 0 & 0 & 0 & 0 & 0 & 0 & 0 & 0 \\
50 & 50 & 150 & 40 & 50 & 2 & 5 & 160 \\
100 & 150 & 500 & 80 & 100 & 4 & 10 & 200 \\
150 & 475 & 650 & 180 & 150 & 14 & 35 & 300 \\
200 & 800 & 800 & 280 & 200 & 24 & 60 & 400 \\
300 & 1600 & - & 565 & 300 & 36 & 90 & 800 \\
400 & 2100 & - & 750 & 3090 & 48 & 120 & 1000 \\
\hline
\end{tabular}


Table 2. Air Quality Index (AQI) evaluation criteria.

\begin{tabular}{ccccccc}
\hline AQI rating & Class 1 & Class 2 & Class 3 & Class 4 & Class 5 & Class 6 \\
\hline AQI standard & $0 \sim 50$ & $51 \sim 100$ & $101 \sim 150$ & $151 \sim 200$ & $201 \sim 300$ & $>300$ \\
Evaluation & Excellent & Good & Mild pollution & Moderate pollution & Heavy pollution & Severe pollution \\
Color & Green & Yellow & Orange & Red & Purple & Brown \\
\hline
\end{tabular}

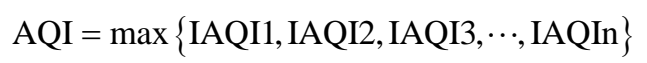

where: IAQI-air quality sub-index; n-pollutant item.

\subsection{Mechanisms of Urbanization Impact on Air Quality}

\subsubsection{Impact of Population Urbanization on Air Quality}

Urbanization has altered population density and lifestyles. Urbanization has resulted in many people moving from the countryside to the cities, resulting in more urban household waste. China currently disposes of waste by incinerating, composting, and landfilling. Domestic waste incineration is the most polluting, producing soot and toxic gases like sulphur dioxide and nitrogen oxides. Simultaneously, increased population density has increased domestic fuel use by residents of fixed urban areas, causing increased emissions of pollutants into the air.

\subsubsection{Impact of Economic Urbanization on Air Quality}

Economic urbanization is reflected in changes in industrial structure, technology, and scale. The industrial structure affects a region's air quality. If secondary industry dominates a region, industrial waste gas emissions often cause serious air pollution issues. Simultaneously, economic urbanization has improved science and technology that can improve energy efficiency, treat and clean factory emissions, and reduce pollution. Moreover, industrial scale allows similar industries to cluster together, allowing the government to unify and set reasonable pollutant emission standards.

\subsubsection{Impact of Land Urbanization on Air Quality}

The industrial dust generated during construction and demolition of urban building facilities, etc., can have a serious impact on the air environment. Urbanization reduces green space, and the city as a whole is less capable of self-purifying pollutants than the countryside or natural environment, which has a much higher proportion of green space. Because it regulates temperature and the air can absorb carbon dioxide, fine particulates, and other harmful substances, urban greening should be included in the urbanization process. Increased urban greenery coverage can help reduce pollutants and improve air quality.

\section{Methodology}

\subsection{Data Sources}

In this paper, we examine the impact of urbanization on the spatial and tempor- 
al evolution of air quality in major cities across the country, using six indicators to assess population, economic, and land urbanization. The number of days with RSP and air quality Class II or better is also used to characterize each city's air pollution status. For example, the proportion of secondary industry, GDP per capita, urban built-up area, and built-up area greenery were obtained from the Hubei Environmental Quality Status Bulletin (2016-2018). Statistics on secondary industry share, GDP per capita, urban built-up area, greening coverage of built-up areas, total year-end urban population and population density were obtained from the National Bureau of Statistics Annual Statistical Bulletin (20032019), the China Urban Statistical Yearbook (2003-2019), and the statistical yearbooks and bulletins of each city.

\subsection{Variable Selection}

This study is about the impact of urbanization on the spatial and temporal evolution of air quality, and therefore the AQI is used as the dependent variable in the model. In a review and summary of the existing literature, it was found that different scholars have selected PM2.5, PM10, $\mathrm{SO}_{2}, \mathrm{NO}_{2}, \mathrm{CO}, \mathrm{O}_{3}$ and other commonly monitored pollutant concentrations to characterize the air pollution status, respectively. In this paper, taking into account the diversity of air pollution and the heterogeneity of pollutants, and referring to the provisions in the Technical Specification for Ambient Air Quality Assessment, AQI is selected to characterize the comprehensive air pollution index, with a higher AQI indicating a more serious pollution level.

Urbanization is a product of continuous economic, social and cultural development, manifesting itself in the expansion of population size, the transformation of industrial structure and changes in land use types, etc. It is a complex and dynamic process. Although the definition of the concept varies from discipline to discipline, the connotation and characteristics of the urbanization system are mostly expanded and synthesized in three aspects: demographic, economic and spatial (Li, Liu, \& Bai, 2003). In this paper, by analyzing the meaning of urbanization, reading the literature on the construction of urbanization index systems, and referring to the indicators that have been used more frequently by researchers in recent years, six indicators were initially selected from three perspectives: demographic urbanization, economic urbanization and land urbanization, and the specific indicators are shown in Table 3.

\subsection{Explanatory Variables}

\subsubsection{Urbanization of the Population}

Population urbanization is the process of decreasing the proportion of rural population while increasing the proportion of urban population (Guo, Wang, \& Gao, 2014). The urbanization rate is calculated using the indicator chosen by (Gao \& Guo, 2018) Population density also refers to the degree of urban population concentration in this study. Increased urban population will inevitably lead 
Table 3. Descriptive statistics of the variables.

\begin{tabular}{|c|c|c|c|c|c|c|}
\hline Primary indicators & Secondary indicators & Units & Mean & $\begin{array}{l}\text { Standard } \\
\text { deviation }\end{array}$ & Minimum & Maximum \\
\hline \multirow{2}{*}{$\begin{array}{c}\text { Economic } \\
\text { urbanization }\end{array}$} & Share of secondary sector & $\%$ & 49.38 & 5.58 & 37.89 & 58.69 \\
\hline & GDP per capita & Yuan & $55,681.00$ & $25,618.76$ & $25,319.00$ & $123,831.00$ \\
\hline \multirow[b]{2}{*}{$\begin{array}{l}\text { Population } \\
\text { urbanization }\end{array}$} & Population density & Persons $/ \mathrm{km}^{2}$ & 3691.83 & 2364.60 & 1376.00 & 9760.00 \\
\hline & $\begin{array}{l}\text { Total urban year-end } \\
\text { population }\end{array}$ & Million people & 224.50 & 138.90 & 68.13 & 619.35 \\
\hline \multirow{2}{*}{ Land urbanization } & Urban built-up area & $\mathrm{km}^{2}$ & 129.94 & 147.80 & 50.00 & 628.11 \\
\hline & Green coverage of built-up areas & $\%$ & 37.59 & 2.80 & 32.37 & 42.31 \\
\hline
\end{tabular}

to increased domestic fuel use and waste generation, with resulting pollutant emissions affecting urban air quality.

\subsubsection{Economic Urbanization}

Economic urbanization is the continuous transformation of human society from an agricultural to an industrialized society, resulting in the continuous transfer of labour from primary to secondary and tertiary industries. Li Jiajia and Luo Nansheng's methodology is used to characterize economic factors in this study. Furthermore, previous research shows that secondary and tertiary industries have a greater direct impact on air quality than primary industries, with a reciprocal relationship between them. This paper uses the share of secondary industry in GDP to characterize the economic structure of Hubei cities.

\subsubsection{Land Urbanization}

The urbanization of land is accompanied by an increase in urban transportation land, residential land, and industrial land, and the industrial dust generated during the construction of urban facilities can have a serious impact on the air environment. On the other hand, an increase in urban land often means a decrease in green space. The city as a whole as a system is much less capable of absorbing and self-purifying pollutants than the countryside or natural environment with a much larger proportion of green space. Therefore the increase of greening coverage in built-up areas helps to reduce the pollutants in urban air and improve the air quality.

\subsection{Modeling}

This paper examines the effects of various urbanization factors on air pollution (AQI values) using panel data for 13 cities in Hubei Province from 2015 to 2017. And according to the previous variable selection, the share of secondary industry, GDP per capita, population density, total city year-end population, urban builtup area, green coverage of built-up area and AQI values are incorporated into the model, respectively. 


\section{Results of the Empirical Study}

\subsection{Annual Change in AQI in Hubei Province 2015-2017}

The data was compiled from the Hubei Province and Wuhan City environmental protection departments (Table 4) to create a line graph of the annual average AQI for each city in Hubei Province. From 2015 to 2018, the annual average AQI values for cities in Hubei have decreased (showing in Figure 1). However, cities like Jingmen have more atypical air quality trends. The annual average AQI in Jingmen suddenly increased in 2018, surpassing the annual average AQI in 2016. According to the People's Government of Jingmen's "2018 Citywide Environmental Quality Situation," the three regions with the highest pollutant concentrations are Zhanghe New District, Dongbao District, and Duodao District. The Zhanghe New District saw the most growth in 2017, focusing on important projects like municipal roads, public works, and public infrastructure like the passenger terminal. As a result of the concentration of various construction projects, industrial dust and exhaust emissions are likely to be the cause of poor air quality.

\subsection{Monthly Change in AQI in Hubei Province 2015-2017}

The monthly average AQI statistics for Wuhan are shown in Table 5 . The monthly AQI trend chart (Figure 2) shows that the three months with the highest AQI values are January, December and February, while the lowest are July, June and

Table 4. Trends in urban ambient air quality dynamics in Hubei Province ("China Air Quality Online Monitoring and Analysis Platform|TrueGas.com” 2021).

\begin{tabular}{ccccc}
\hline \multirow{2}{*}{ City } & \multicolumn{4}{c}{ Annual Average Ambient Air Quality Index (AQI) } \\
\cline { 2 - 5 } & 2015 & 2016 & 2017 & 2018 \\
\hline Wuhan & 103.42 & 92.50 & 89.33 & 82.42 \\
Huangshi & 93.83 & 85.00 & 82.58 & 76.83 \\
Shiyan & 79.00 & 77.92 & 73.58 & 74.33 \\
Yichang & 98.00 & 91.75 & 90.42 & 83.42 \\
Xiangyang & 111.08 & 101.33 & 100.92 & 94.08 \\
Ezhou & 100.67 & 93.17 & 84.17 & 79.75 \\
Jingmen & 101.50 & 87.92 & 83.08 & 89.17 \\
Xiaogan & 100.42 & 80.42 & 83.92 & 80.83 \\
Jingzhou & 101.83 & 92.92 & 86.33 & 81.00 \\
Huanggang & 89.83 & 83.75 & 84.92 & 81.17 \\
Xianning & 87.17 & 79.17 & 78.83 & 71.58 \\
Suizhou & 96.25 & 87.58 & 76.92 & 79.08 \\
Average & 96.92 & 87.79 & 84.58 & 81.14 \\
\hline
\end{tabular}




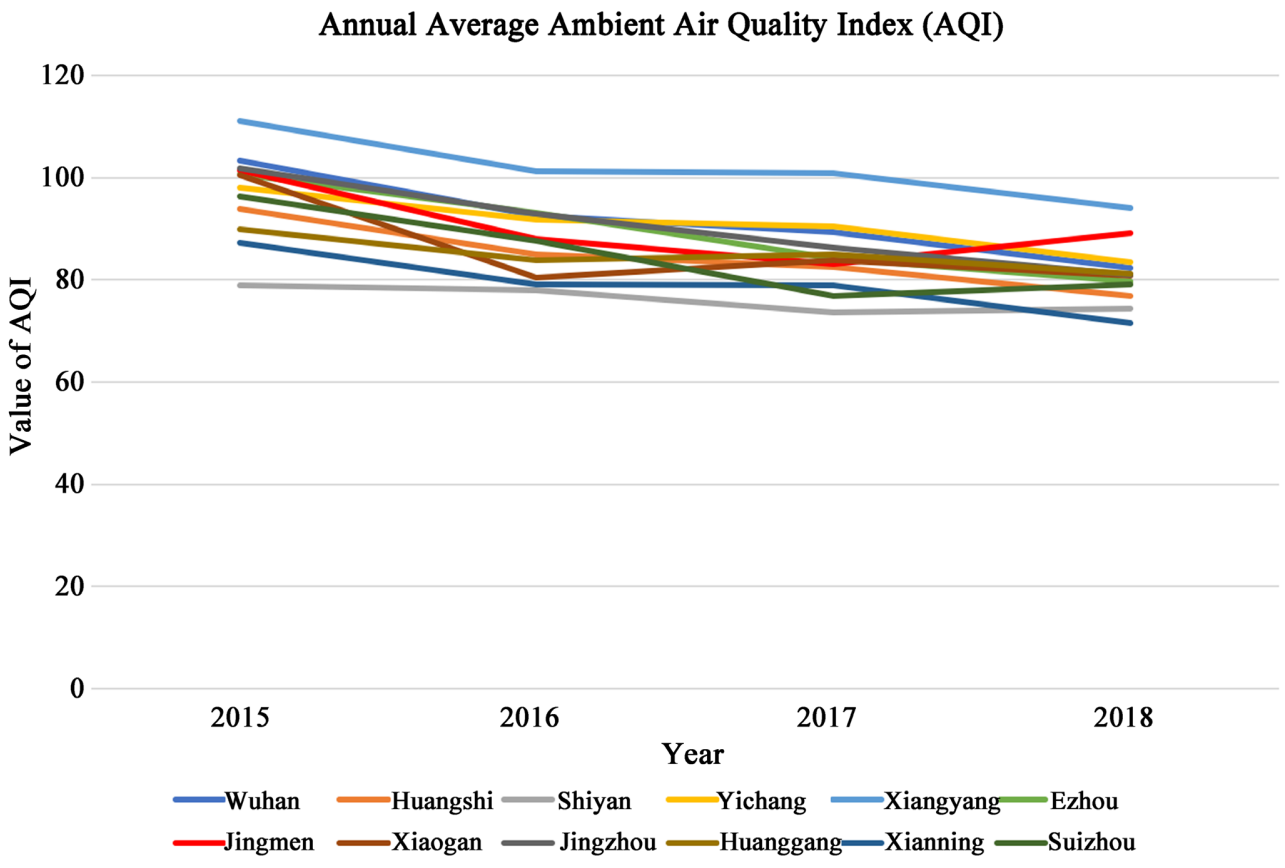

Figure 1. Folding graph of annual average air quality index by the city in Hubei province.

Table 5. Trends in urban ambient air quality dynamics in Hubei province.

\begin{tabular}{ccccccccccccc}
\hline \multirow{2}{*}{ Year } & \multicolumn{10}{c}{ Monthly Average Ambient Air Quality Index } \\
\cline { 2 - 13 } & January & February & March & April & May & June & July & August & September & October & November & December \\
\hline 2014 & 229 & 122 & 110 & 87 & 112 & 119 & 81 & 78 & 74 & 123 & 105 & 114 \\
2015 & 161 & 142 & 94 & 87 & 101 & 73 & 76 & 90 & 92 & 101 & 78 & 146 \\
2016 & 144 & 113 & 115 & 76 & 76 & 69 & 70 & 86 & 94 & 60 & 84 & 123 \\
2017 & 119 & 101 & 94 & 80 & 104 & 75 & 63 & 65 & 74 & 62 & 105 & 130 \\
2018 & 116 & 89 & 78 & 65 & 63 & 96 & 66 & 82 & 68 & 80 & 88 & 98 \\
2019 & 125 & 87 & 79 & & & & & & & & & \\
\hline
\end{tabular}

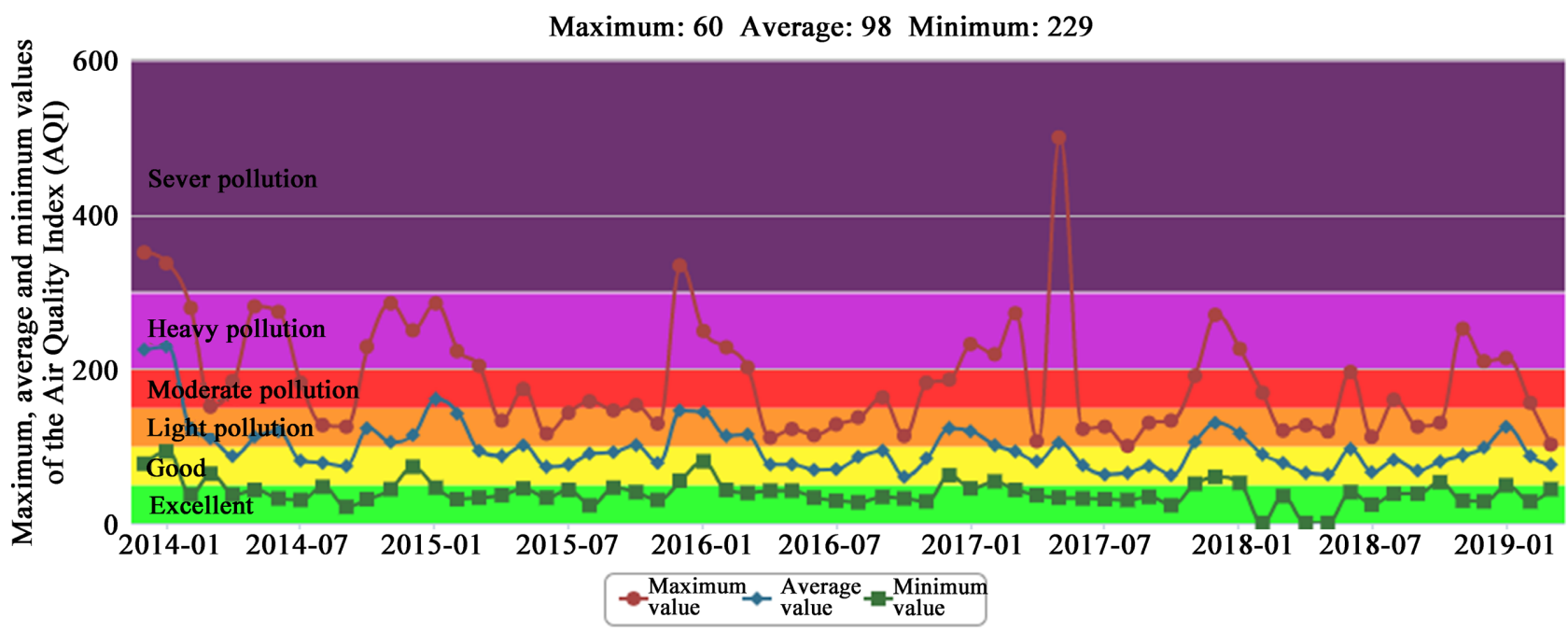

Figure 2. The monthly trend of Wuhan air quality index (AQI). 
August. The overall trend curve shows a " $U$ " shape. The overall trend curve shows a " $U$ " shape, with the worst air quality in winter and the best air quality in summer. In winter, the average air quality in March reached level 3 or above, with the worst month of January reaching level 5, and the monthly average AQI was 229, with the number of hours with level 2 or below (excellent air quality) accounting for only $17 \%$. During the summer months, the percentage of hours with excellent and good air quality was above $90 \%$, especially in June when it reached $97.1 \%$. Scholars such as Jun Zhang believe that this phenomenon is due to more stable weather conditions in winter, less convective and increased coal burning during the heating season, while in summer, convective weather increases and meteorological conditions are favourable for pollutant removal and dilution. The monthly AQI trends in other cities are generally similar to Wuhan's, with significant " $U$ " shaped characteristics, so the attached graphs will not be repeated. As seasonal factors are climatic factors and not closely related to the urbanization process, this paper does not include quarters in the study model when discussing the impact of urbanization on air quality.

\subsection{Spatial Patterns of Air Quality in Hubei Province, 2013-2017}

\subsubsection{The Overall Air Quality Environment Shows a Bicentre Ring Distribution}

The annual average AQI values of 13 prefecture-level cities in Hubei province were imported into ArcGIS software to produce three maps of prefecture-level city AQI distribution. The three maps (Figure 3) show a bicentre ring distribution of air pollution in Hubei Province. Xiangyang, with an annual average AQI of 111.08 in 2015, is followed by Jingmen and Jingzhou, both with an annual average AQI of over 100. Wuhan, in eastern Hubei province, has the second-highest annual average AQI 103.42, after Xiangyang. Xiaogan and Ezhou have AQI values over 90 .

\subsubsection{The Western Centre of Air Pollution Shifted to the Southwest, with a Trend of Diffusion from the Eastern Centre}

From 2015 to 2017, the pollution centre in Hubei Province shifted, despite the general bicentre ring distribution. Yichang City, southwest of Xiangyang City, became the pollution centre of the western urban agglomeration, while Jingmen and Jingzhou, both adjacent to Yichang City, saw their AQI values drop year after year.

The eastern urban agglomeration's air pollution, once centred on Wuhan, has diffused, with good air quality in surrounding cities. Over the next four years, the eastern urban agglomeration's overall air quality index declined, with $\mathrm{Wu}$ han and Xiaogan showing particularly significant drops. From 2015 to 2016, Xiaogan City had the largest annual average AQI decrease. According to the 2015 Xiaogan City Environmental Status Bulletin, the city spent RMB 14.113 million on pollution treatment in 2015. Desulphurization and denitrification of Hanchuan power plant units, as well as flue gas desulphurization of Hubei Yihua 

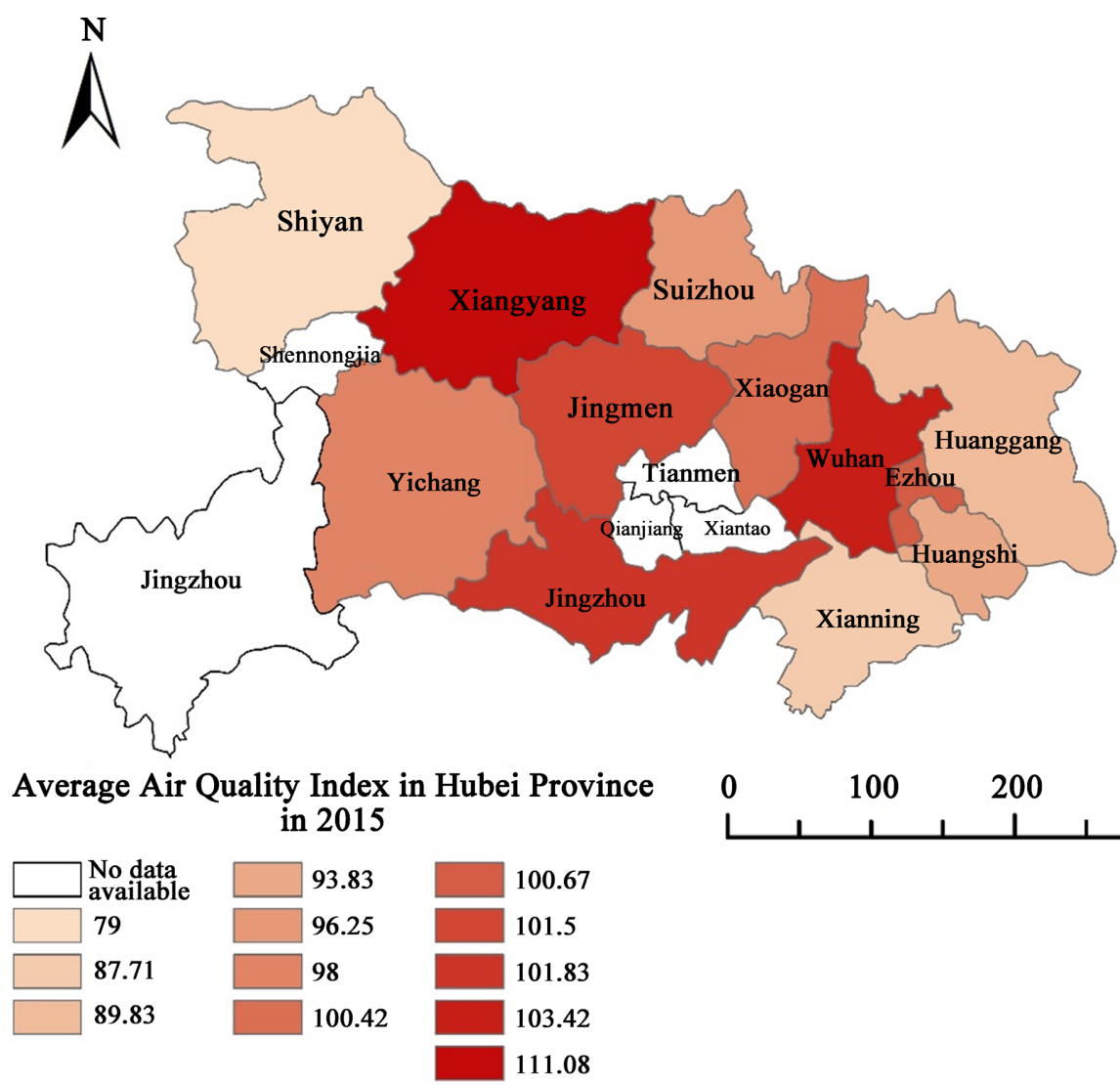

Kilomiterers

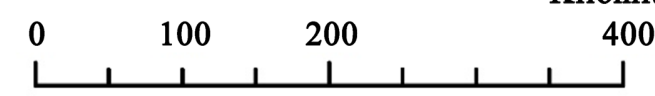
400

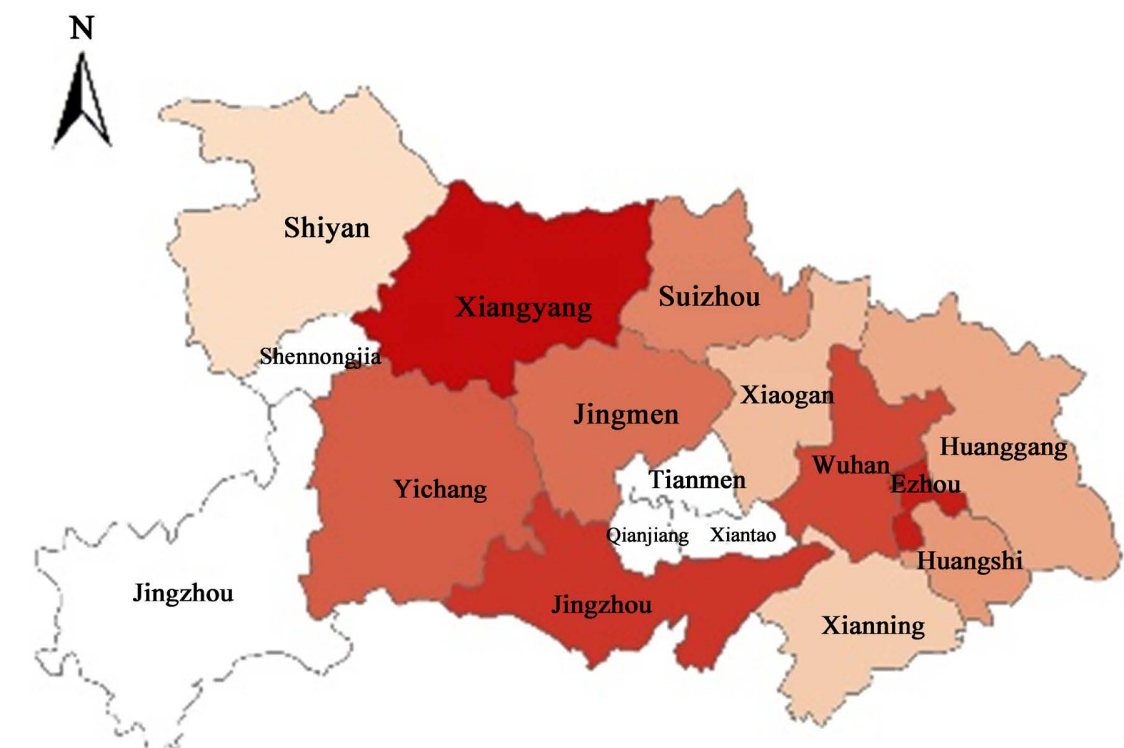

Average Air Quality Index in Hubei Province in 2016

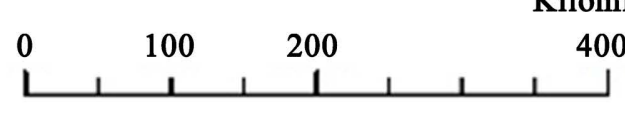

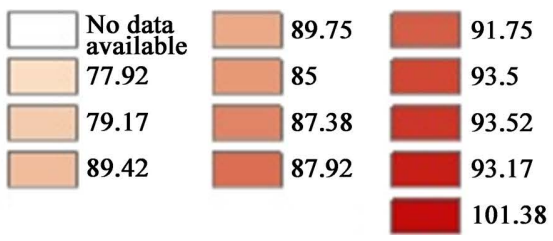




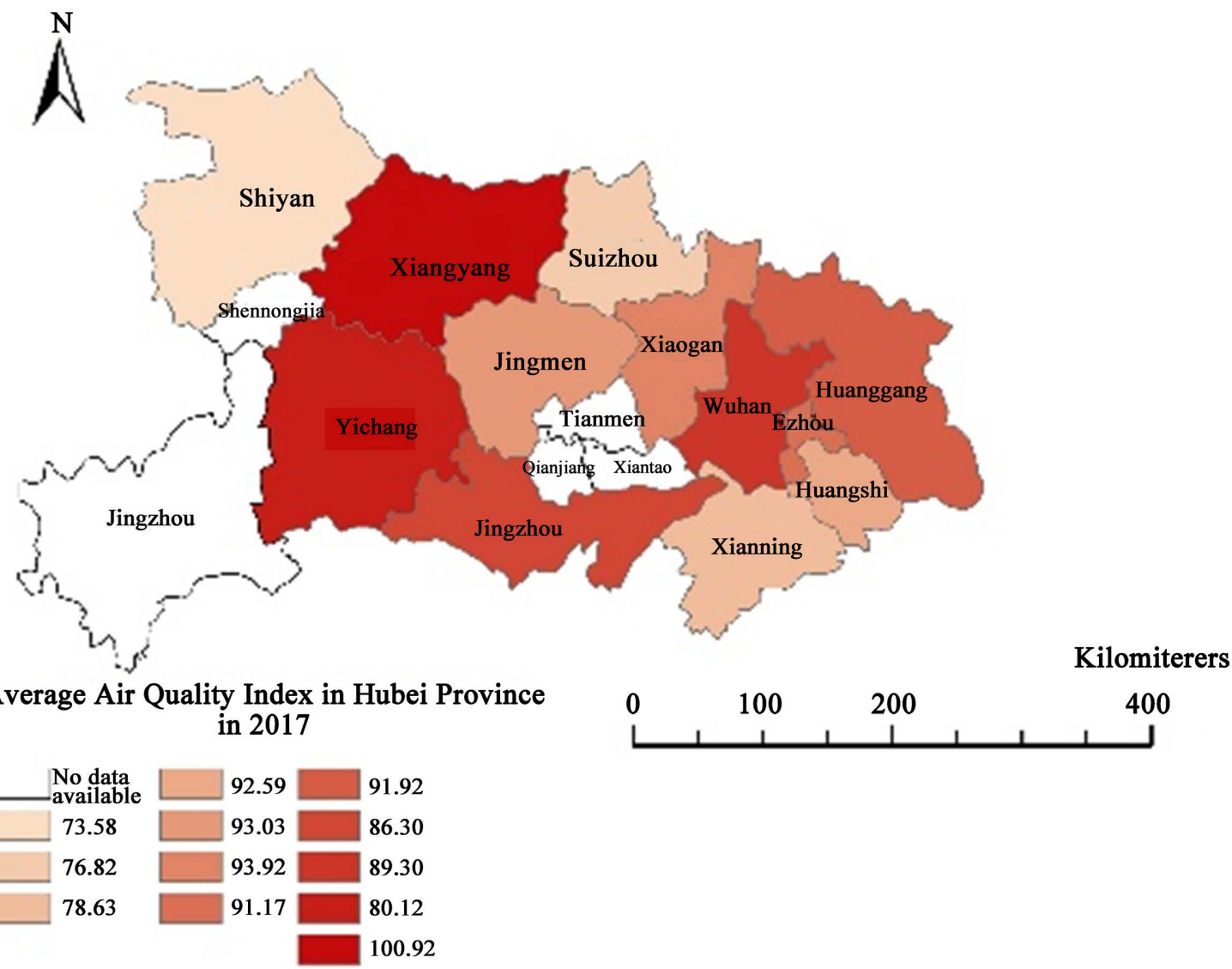

Figure 3. Map of the spatial distribution of AQI in Hubei province 2015-2017.

Shuanghuan Company, were also successfully implemented. The annual average AQI of Xiaogan City has fallen significantly since 2015, and the gap between Wuhan City and the surrounding prefecture-level cities has also narrowed, as pollution has spread to the periphery.

\subsection{Empirical Results}

The regression analysis of urbanization indicators and air quality in 13 prefecture-level cities in Hubei Province was conducted using Stata software. The fixedeffect model and random effect model were chosen respectively. After the Hausman test (results in Table 6), the p-value was greater than 0.05 , and the original hypothesis could not be rejected, so the random effect was chosen (results in Table 7).

A random-effects regression was constructed with $A Q I$ as the dependent variable, secondary industry structure, GDP per capita, population density, year-end urban population, built-up area, and built-up area greenery coverage as independent variables. The p-value of 0.0005 was less than 0.05 , indicating that the model passed the test.

The $\mathrm{p}$-value for the independent variable $\mathrm{X}_{1}$ is 0.000 , and the $\mathrm{p}$-value for the independent variable $\mathrm{X}_{2}$ is 0.005 , both of which are less than 0.05 . Therefore, the 
Table 6. Hausmann test results.

\begin{tabular}{|c|c|c|c|c|}
\hline & $\begin{array}{l}\text { (b) } \\
\mathrm{Fe}\end{array}$ & $\begin{array}{l}\text { (B) } \\
\text { re }\end{array}$ & $\begin{array}{c}(\mathrm{b}-\mathrm{B}) \\
\text { Difference }\end{array}$ & $\begin{array}{c}\operatorname{Sqrt}\left(\operatorname{diag}\left(V_{-} b-V_{-} B\right)\right. \\
\text { S.E. }\end{array}$ \\
\hline Variable $\mathrm{X}_{1}$ share of secondary sector & 0.14564 & 1.90075 & -1.75510 & 0.67509 \\
\hline Variable $\mathrm{X}_{2}$ GDP per capita & -0.00081 & -0.00046 & -0.00035 & 0.00033 \\
\hline Variable $\mathrm{X}_{3}$ population density & 0.00599 & 0.00091 & 0.00508 & 0.00536 \\
\hline Variable $\mathrm{X}_{4}$ year-end urban population & -0.50323 & -0.00488 & -0.49835 & 0.28468 \\
\hline Variable $\mathrm{X}_{5}$ area of built-up area & 0.1750 & 0.09535 & 0.07961 & 0.18271 \\
\hline Variable $\mathrm{X}_{6}$ green coverage of built-up areas & -0.23415 & -1.12971 & 0.89556 & 0.75510 \\
\hline \multicolumn{5}{|c|}{$\mathrm{b}=$ Consistent under Ho and Ha; obtained from xteg; } \\
\hline \multicolumn{5}{|c|}{$\mathrm{B}=$ Inconsistent under Ha, efficient under Ho; obtained from xtreg; } \\
\hline \multicolumn{5}{|c|}{ Test: Ho: difference in coefficients not systematic; } \\
\hline \multicolumn{5}{|l|}{$\operatorname{Chi}^{2}(6)=(b-N)^{\prime}\left[V_{-} b-V_{-} B^{\wedge}(-1)\right](b-B)=11.72$} \\
\hline $\begin{array}{l}\text { Prob }>\mathrm{chi}^{2}=0.0686 \\
\text { (V b-V B is not positive definite) }\end{array}$ & & & & \\
\hline
\end{tabular}

Table 7. Stata random effects model regression results.

\begin{tabular}{|c|c|c|c|c|c|c|}
\hline Variable Y & Coef. & Std. & Err. & $\mathrm{Z}$ & $\mathbf{P}>|z|$ & [95\%Conf.Interval] \\
\hline Variable $\mathrm{X}_{1}$ share of secondary sector & 1.90075 & 0.49223 & 3.86 & 0.000 & 0.93598 & 2.86551 \\
\hline Variable $\mathrm{X}_{2}$ GDP per capita & -0.00045 & 0.00016 & -2.83 & 0.005 & -0.00079 & -0.00014 \\
\hline Variable $\mathrm{X}_{3}$ population density & 0.00091 & 0.00160 & 0.57 & 0.570 & -0.00223 & 0.00405 \\
\hline $\begin{array}{l}\text { Variable } \mathrm{X}_{4} \text { number of urban population at the } \\
\text { end of the year }\end{array}$ & -0.00488 & 0.05630 & -0.09 & 0.931 & -0.11524 & 0.10547 \\
\hline Variable $\mathrm{X}_{5}$ area of built-up area & 0.09535 & 0.05835 & 1.63 & 0.102 & -0.01902 & 0.20972 \\
\hline Variable $\mathrm{X}_{6}$ green coverage of built-up areas & -1.12972 & 0.81259 & -1.39 & 0.164 & -2.72236 & 0.46293 \\
\hline _cons & 49.60939 & 39.08255 & 1.27 & 0.204 & -26.99101 & 126.20980 \\
\hline sigma_u & & & & 5.65038 & & \\
\hline sigma_e & & & & 4.20024 & & \\
\hline \multicolumn{7}{|l|}{ Random-effects GIS regression } \\
\hline Group variable: regin & \multicolumn{6}{|c|}{ Number of obs $=36$} \\
\hline R-sq: & \multicolumn{6}{|c|}{ Number of groups $=12$} \\
\hline within $=0.5487$ & \multicolumn{6}{|c|}{ Wald $\operatorname{chi}^{2}(6)=24.04$} \\
\hline between $=0.1734$ & \multirow{2}{*}{\multicolumn{6}{|c|}{$\begin{array}{l}\text { Prob }>\text { chi } 2=0.0005 \\
\left.\text { corr }\left(u_{\_} \text {i, }, X\right)=0 \text { (assumed }\right)\end{array}$}} \\
\hline overall $=0.2889$ & & & & & & \\
\hline
\end{tabular}

proportion of secondary industry structure and GDP per capita are important factors affecting AQI, and there is a positive relationship between the independent variable $\mathrm{X}_{1}$ and AQI and a negative relationship between the independent variable $\mathrm{X}_{2}$ and $\mathrm{AQI}$. In other words, the larger the proportion of secondary industry structure, the more pollutants produced by industry, the higher the AQI 
value and the worse the air quality. GDP per capita is significantly and negatively correlated with AQI, with higher GDP per capita improving air quality in cities, i.e., economic development promotes the improvement of the urban air environment. In 2013, the GDP per capita of Hubei province reached US\$6381.7, which is the critical point for positive environmental quality transformation. The higher the level of scientific and technological development, the higher the total factor production efficiency and resource use efficiency, and the lower the pollution emissions per unit of output, according to the stage-by-stage rule of technological renewal.

The $\mathrm{p}$-values for independent variables $\mathrm{X}_{3}, \mathrm{X}_{4}, \mathrm{X}_{5}$ and $\mathrm{X}_{6}$ are all greater than 0.05 , so population density, year-end urban population, built-up area and builtup area green coverage do not have a significant effect on AQI. The resulting regression equation: $\mathrm{Y}=49.60939+$ variable $\mathrm{X}_{1}$ (secondary industry structure) * $1.900745+$ independent variable $\mathrm{X}_{2}(\mathrm{GDP}$ per capita $) *-0.0004651$.

\section{Findings and Discussion}

\subsection{Temporal Evolution of Air Quality in Hubei Province}

The statistical description of the annual and monthly average AQI data for 13 prefecture-level cities in Hubei Province concludes that the annual average AQI of Hubei cities is on an overall decreasing trend and the air quality is gradually getting better. However, the change trend in the air environment should not lead to a relaxation of relevant environmental policies and a weakening of environmental management. This is to avoid a rebound in AQI values as in the case of Jingmen. The monthly average AQI of Hubei cities varies significantly from quarter to quarter, showing a "U" shape overall. AQI values reach a trough in July and a peak in winter. This quarterly trend is also consistent with the results of existing studies.

\subsection{Spatial Evolution Characteristics of Air Quality in Hubei Province}

A bicentre ring distribution characterises the spatial distribution of air quality in Hubei Province. The western urban agglomeration is centred on Xiangyang, while the eastern urban agglomeration is centred on Wuhan, with the air quality index gradually decreasing in all directions along the centre. In recent years, there has been a shift in the centre of air pollution, with Suizhou acting as the boundary between the eastern and western urban agglomerations, with the centre of pollution in the western urban agglomeration gradually moving towards Yichang, southwest of Xiangyang. In fact, the AQI values in Yichang have been decreasing year by year over the past four years, but the decrease is less than that in Xiangyang, the original pollution centre, and is still slightly higher than that in the surrounding cities, so the overall spatial distribution shows a trend of shifting towards Yichang. In the eastern part of the city cluster, the AQI values of Wuhan, 
the previous centre of pollution, have decreased the most and are basically similar to those of the neighboring cities, so the centre of pollution has become less obvious and has shown a tendency to spread in all directions.

\subsection{Factors Influencing Urbanization on Air Quality}

From the results of the analysis in the text we know that GDP per capita has a negative correlation with AQI, the higher the GDP per capita, the better the air quality. The percentage of secondary industry has a positive correlation with AQI. In other words, the greater the proportions of the secondary industry, the more pollutants are produced by the industry, the higher the AQI value and the worse the air quality. Therefore, changing the industrial structure, which is dominated by the secondary industry, has a significant effect on improving the air environment. Take Jingmen, for example, which has seen large fluctuations in AQI data in recent years. In 2015, Jingmen ranked first in Hubei Province in terms of air quality, and in December of the same year, it also ranked fourth in the real-time ranking of the worst-quality cities in the country as shown on the air quality monitoring website. Because of Jingmen's historical industrial structure, which is dominated by secondary industries, and its energy consumption structure, which is dominated by coal, a large number of air pollutants are emitted, making regional compound pollution characterized by fine particulate matter (PM2.5) and ozone $\left(\mathrm{O}_{3}\right)$ increasingly prominent. Still, before 2015, Jingmen had taken a series of measures to improve air quality. During "the $12^{\text {th }}$ Five-Year Plan" period, the proportion of light industry in Jingmen increased by 11.1 percentage points. During the five-year period, the city's energy consumption share of light industry increased by 2.8 percentage points. In 2015, industrial energy consumption in Jingmen accounted for $74.4 \%$ of the city's total social energy consumption, down 10.4 percentage points from 2010. Among them, the energy consumption of the four major high-energy-consuming industries (non-metallic mineral products industry, chemical raw materials and chemical products manufacturing industry, petroleum processing industry, and production and supply of electricity and heat) accounted for 4.6 percentage points of the total energy consumption of all industries above the scale. As a result, the air quality situation in Jingmen city could only improve significantly after 15 years. However, in 2017 the AQI rebounded again due to the concentration of a large number of construction projects mentioned above. This shows that waste emissions and industrial dust from the secondary industry have seriously impacted air quality.

\section{Conclusion and Recommendation}

\subsection{Conclusion}

In this paper, six indicators are selected based on the existing literature. The three dimensions of urbanization in terms of population, economy, and land are used to measure the level of urbanization in each city. Then the AQI of 13 prefecture-level cities in Hubei province from 2015-2018 was used as the basis to 
analyze the annual and monthly changes of AQI values in each city in Hubei province over the three years, and ArcGIS was used to make a spatial distribution map of AQI values. The urbanization indexes were then regressed with AQI values to study the influence of urbanization level on the spatial and temporal evolution of air quality in each prefecture-level city in Hubei province.

According to statistical data, the annual average AQI values of 13 prefecturelevel cities in Hubei have generally shown a downward trend in recent years. The monthly average AQI shows a "U-shaped" characteristic, with the most severe air pollution in winter and the best air quality in summer. From the GIS map, the spatial distribution of urban air pollution in Hubei province shows an overall bicentered ring distribution. The city cluster in the west of Hubei province is centered on Xiangyang city, while the city cluster in the east is centered on $\mathrm{Wu}$ han city. The air quality index gradually decreases from the center to the surrounding area and finally forms a ring. However, there is a certain trend of the spatial shift of air pollution centers in recent years. The regression test of urbanization index and AQI shows that the two explanatory variables of the secondary industry share and GDP per capita have significant effects on AQI values.

\subsection{Policy Recommendations}

\subsubsection{Industrial Structure Adjustment and Optimization}

Since the secondary industry is the main factor that increases the AQI value, adjusting and optimizing the regional industrial structure is one of the most important aspects of improving the air environment. The layout of the industry should be balanced, taking into account not only the economic benefits of the industry, but also the local air quality situation. And it should promptly eliminate backward production capacity and reduce excess capacity. The government should strictly abide by the national industrial policy catalogue and not approve or record any projects with serious overcapacity. The government should also take comprehensive measures to rectify "scattered and disorganized" enterprises and clusters.

\subsubsection{Improve Energy Use Efficiency}

While promoting urbanization, we should focus on building infrastructure and promoting the development of science and technology. We should replace old, outdated energy sources with new, green ones, and improve energy use through advanced technology to reduce energy waste and pollutant emissions caused by inadequate energy consumption. And the pollutants caused by industry should be treated and processed to reduce toxic gases into the atmosphere.

\subsubsection{Promote Urbanization in an Appropriate Manner}

Urbanization is a natural stage of social development, involving multidimensional changes in land, population, economy and society, and cannot be achieved overnight. The government should conduct scientific research and formulate development plans according to local natural conditions, resource endowments, the 
current state of economic and social development and the strategic positioning of regional development, as well as build a scientific and healthy model of urbanization development, rather than rushing for quick success and blindly promoting urbanization at a rapid pace. The focus should also be on the urban problems caused by urbanization, such as traffic congestion, housing tension and shortage of means of living. These problems indirectly contribute to the deterioration of air quality through emissions from car exhaust, dust from construction work, fuel burning, etc.

\section{Conflicts of Interest}

The author declares no conflicts of interest regarding the publication of this paper.

\section{References}

Cai, Y. J., \& Li, T. P. (2015). An Empirical Analysis of Urban Air Quality Influencing Factors. Environmental Protection and Circular Economy, 35, 65-68+71.

Chan, C., \& Yao, X. (2008). Air Pollution in Megacities in China. Atmospheric Environment, 42, 1-42. https://doi.org/10.1016/j.atmosenv.2007.09.003

Ding, L., Liu, C., Huang, Y. L., Chen, K. L., \& Zeng, K. F. (2016). Spatial and Temporal Evolution Patterns of Urban Ambient Air Quality in Hubei Province and Influencing Factors. Economic Geography, 36, 170-178.

Gao, M, \& Guo, F. (2018). A Study on the Impact of Urbanization on Air Quality-A Case Study of Beijing-Tianjin-Hebei Urban Agglomeration. Environmental Economics, 3, 88-105.

Guo, S. H., Wang, F. X., \& Gao, M. (2014). Study on the Spatio-Temporal Coupled Coordination Relationship between Population Urbanization and Land Urbanization in Shandong Peninsula. Economic Geography, 34, 2-78.

Li, J. W., Liu, Y. B., \& Bai, S. J. (2003). Analysis of the Characteristics of Urbanisation Level and Influencing Factors in Hubei Province. Economic Geography, 23, 782-785.

Ma, S.L., Han, J., \& Yang, S. C. (2016). City Size, Agglomeration and Air Quality. China Population-Resources and Environment, 26, 12-21.

Qiu, Y., \& Huang, D. (2020). Influence of Urbanisation Level on Haze Pollution. Journal of Hunan University of Science and Technology (Social Science Edition), 23, 59-69.

Sun, K. X., \& Zhong, M.C. (2017). Environmental Regulation, Industrial Structure Optimization and Urban Air Quality. Journal of Zhongnan University of Economics and Law, 63, 72-159.

Sun, Y., Pan, Y. P., Li, X. R., Zhu, R. H., \& Wang, Y. S. (2011). Simultaneous Observation of Atmospheric Particulate Matter Chemical Composition in Typical Beijing, Tianjin and Hebei. Environmental Science, 32, 2732-2740.

Wang, G. L., Xue, J. J., \& Zhang, J. Z. (2016). Characteristics of the Spatial and Temporal Distribution of Air Pollution in Beijing, Tianjin and Hebei in 2014 and Analysis of Its Main Causes. Meteorology and Environmental Science, 39, 34-42.

Wang, X. J., Xie, G. G., \& Yue, S.P. (2015). Impact of Economic Growth and Population Agglomeration on Urban Ambient Air Quality and Regional Divergence-Example of 74 Cities Implementing New Air Quality Standards in the First Phase. Economic Geography, 35, 71-76+91. 
Xiao, Y., Tian, Y. Z., Xu, W. X., Wu, J. J., Tian, L., \& Liu, J. (2017). Spatial and Temporal Distribution Characteristics of Air Quality in China over the Past Decade. Journal of Ecology and Environment, 26, 243-252.

Xu, Y. T., Liu, X. Z., \& Wang, Z. B. (2019). Spatial and Temporal Distribution Characteristics of Urban Air Quality in China Based on AQI Index. Journal of Guangxi Normal University (Natural Science Edition), 37, 187-196. 